\title{
Developmental Dynamics of Meloidogyne hapla in Washington Wine Grapes
}

\author{
Katherine E. East, ${ }^{1}$ Inga A. Zasada, ${ }^{2}$ R. Paul Schreiner, ${ }^{2}$ and Michelle M. Moyer ${ }^{1, \dagger}$ \\ ${ }^{1}$ Department of Horticulture, Washington State University Irrigated Agriculture Research and Extension Center, Prosser, WA \\ 99350; and ${ }^{2}$ United States Department of Agriculture-Agriculture Research Service (USDA-ARS), Horticultural Crops Research \\ Laboratory, Corvallis, OR 97330
}

\begin{abstract}
Meloidogyne hapla is the most prevalent plant-parasitic nematode in Washington state wine grape vineyards. Understanding the developmental dynamics of $M$. hapla can improve the timing of diagnostic sampling and nematicide application. Three Vitis vinifera vineyards in Washington were sampled March 2015 to March 2017 to determine the developmental dynamics of $M$. hapla by measuring second-stage juveniles (J2) in soil, eggs and adult females in roots, and fine root tips. A model of $M$. hapla $\mathrm{J} 2$ development based on soil growing degree days using a base temperature $\left(\mathrm{T}_{\mathrm{b}}\right)$ of $0^{\circ} \mathrm{C}\left(\mathrm{GDD}_{\text {soil }}\right)$ and a start date of 1 March was

developed. This model was validated at two additional vineyards in Washington and was robust with $R^{2}$ values $>0.74$. M. hapla has one generation per year and overwinters primarily as the $\mathrm{J} 2$ infective stage. Juvenile populations declined after 1 March, reaching their lowest density in early July and reaching a maximum density over the winter. $M$. hapla egg and root tip densities reached a maximum in early August. The number of females per root tip did not vary throughout the year. A single generation with defined peaks in $\mathrm{J} 2$ population densities will allow for specific timing of nematicide interventions.
\end{abstract}

Root-knot nematodes (Meloidogyne spp.) have been attributed to various vineyard maladies, including general vine decline and replant disorders (McKenry et al. 1994; Raski et al. 1973). Washington state is the second largest producer of wine grapes (Vitis vinifera) in the United States (NASS 2017). Although relatively young, the Washington wine grape industry will soon be facing a period of intensive replanting, as older vineyards become less productive and alternative varieties are wanted by winemakers. Eastern Washington, where over $99 \%$ of the state's grape acreage is planted, is arid and requires irrigation for vineyard production. Water is strictly regulated in the state, and this limits the availability of new land for farming use. Thus, as vineyards age and new plantings become increasingly limited to replant sites, poor establishment of young vines, long term loss of productivity, and increased management costs owing to nematode parasitism (Nicol et al. 1999; Raski et al. 1965) will be key factors influencing long-term vineyard health and economic viability in the region.

Root-knot nematodes are obligate endoparasites of plant roots. They hatch from eggs in the soil as motile, infective second-stage juveniles (J2). Juveniles move within the water film on the surface of soil particles until they locate a root tip. J2 invade the plant root and move through the root before locating parenchyma cells in the root cortex (Eisenback 1985). There, J2 feed and elicit the modification of plant cortical cells to form "giant cells," which are enlarged cytoplasm-dense feeding cells. The nematodes molt through two additional juvenile stages to become adults, which are usually female. Males may form instead of females under stressful conditions (Eisenback 1985). Females will continue to feed from the giant cells

${ }^{\dagger}$ Corresponding author: M. M. Moyer; michelle.moyer@wsu.edu

Funding: Funding was provided by USDA National Institute of Food and Agriculture HATCH project \#0612 and the Washington State Grape and Wine Research Program; funding sources include the Washington State Wine Commission, Auction of Washington Wines, State Liter Tax, and/or Washington State University Agriculture Research Center.

*The $\boldsymbol{e}$-Xtra logo stands for "electronic extra" and indicates that one supplementary figure is published online.

Accepted for publication 19 November 2018.

() 2019 The American Phytopathological Society and lay eggs in a gelatinous matrix outside or just inside the root surface. Aboveground symptoms of root-knot nematode infestation can resemble the symptoms of water stress, or may cause lower yield, lower vigor, and premature leaf senescence. In new plantings, where young vines do not have an established root system, nematodes may severely stunt or kill the plants (Taylor and Sasser 1978).

In Washington state, the northern root-knot nematode, Meloidogyne hapla (Chitwood 1949), is present in 60\% of surveyed vineyards (Zasada et al. 2012). M. hapla is the most common root-knot nematode north of $39^{\circ} \mathrm{N}$ in the United States (Taylor and Buhrer 1958) and is generally found between 34 and $47^{\circ} \mathrm{N}$ (Eisenback et al. 1981). Most other grape-growing regions are concerned with Meloidogyne species other than M. hapla, predominantly M. arenaria, $M$. javanica, and $M$. incognita. M. hapla and M. chitwoodi, the two species found in Washington state, regularly survive soil temperatures below $0^{\circ} \mathrm{C}$, whereas $M$. incognita, $M$. javanica, and $M$. arenaria do not survive soil temperatures below $10^{\circ} \mathrm{C}$ and are absent from Washington state (Van Gundy 1985). In a 3-year microplot experiment in Washington, $M$. hapla readily reproduced on $V$. vinifera, although infection did not translate into a difference in vine biomass (Howland et al. 2015). In a greenhouse study, M. hapla reduced shoot and root dry matter of newly planted vines by 29 and $43 \%$, respectively, compared with vines without nematodes (Schreiner and Zasada, unpublished data). The long-term impacts of M. hapla parasitism on vine health and productivity are not known. The critical threshold in Washington for wine grapes proposed by Santo (unpublished data) is 100 M. hapla $\mathbf{J} 2$ per $250 \mathrm{~g}$ of soil. M. hapla $\mathbf{J} 2$ density in soil may change over time, so optimizing sample timing to when $\mathrm{J} 2$ are near maximum in soil may help give an accurate assessment of risk and better inform management decisions.

Current diagnostic sample timing and nematicide application timing in grapes are based primarily on information from California, where the major tropical species $M$. incognita, $M$. javanica, and $M$. arenaria are the primary concern. These species and the temperate $M$. hapla differ in their activity at different temperatures, including reproduction, life cycle, and overwintering capability of life stages (Daulton and Nusbaum 1961; Lyons et al. 1975; Melakeberhan et al. 1989; Thomason 1962; Vrain et al. 1978); therefore, it is not possible to directly draw management concepts (such as application timing) from these species to M. hapla. In the Pacific Northwest, the other temperate species is $M$. chitwoodi, which is an economically important parasite of potato (Ingham et al. 2018). This nematode has been shown to have three or more generation cycles per season 
(Pinkerton et al. 1991), similarly to M. incognita, which can have multiple generations within a season/year (de Guiran and Ritter 1979). The rate of plant-parasitic nematode development is dependent on its environment, particularly soil temperature and moisture (Wallace 1966). The developmental biology of M. hapla has not been explored.

Understanding the population dynamics of M. hapla in Washington state vineyards is important to inform selection of sample times for diagnostic purposes and to improve the timing of control measures. The life stage of $M$. hapla most vulnerable to nematicides is the infective $\mathrm{J} 2$ stage. The $\mathrm{J} 2$ stage is free-living in soil and would be more likely to contact a soil-applied nematicide as opposed to egg or adult female stages, which are protected by the gelatinous matrix and root, respectively. However, the nature of the life cycle of $M$. hapla in Washington vineyards is unknown. The objectives of this study were (i) to characterize the life cycle of $M$. hapla during the vineyard growing season in eastern Washington, and (ii) to use that information to develop a model that would improve the timing of nematicide application for $M$. hapla management in northern temperate viticulture regions.

\section{Materials and Methods}

Experimental design and vineyard sampling. Three commercial vineyards, each with $M$. hapla, were selected for inclusion in the study. Sites included (i) a 30-year-old own-rooted Vitis vinifera 'Riesling' vineyard located near Mattawa, WA, that was sampled for model development in both 2015 and 2016 (Mattawa); (ii) a 15-year-old $V$. vinifera 'Cabernet Sauvignon' vineyard in Alderdale, WA, that was sampled in 2015 and used for model validation (Alderdale); and (iii) a 36-year-old $V$. vinifera 'Riesling' vineyard in Prosser, WA, that was sampled in 2016 and also used for model validation (Prosser). Within each vineyard, five 150-vine sampling plots were established. At each sampling date, 10 vines within each plot were sampled from 10 15-vine sections. Each individual vine was sampled at most four times over 2 years of data collection. One soil core per vine, $2.5 \mathrm{~cm}$ diameter by $45 \mathrm{~cm}$ deep, containing soil and roots, was collected from under drip emitters, where the majority of M. hapla are known to be concentrated (Howland et al. 2014); the 10 soil cores per plot were combined into a single composite sample, with five composite samples collected per site at each sampling date. Samples were collected weekly during the growing season (April to September) and monthly from October to March, for a total of 150 samples from each site per year. Vine phenology was noted at each sampling date. Sampling began in March 2015 and ended in March 2017.

$M$. hapla $\mathbf{J} 2$ and egg extraction and enumeration. A 250-g subsample of soil containing roots was processed to extract $M$. hapla J2 and roots from soil using a semiautomatic elutriator (Seinhorst 1962). Roots were captured on a 500- $\mu \mathrm{m}$ sieve and M. hapla $\mathrm{J} 2$ on a $37-\mu \mathrm{m}$ sieve. The contents collected on the $37-\mu \mathrm{m}$ sieve were backwashed into a 50-ml tube and the resulting liquid cleared of soil particles and debris using a centrifugation-flotation technique (Jenkins 1964). Extracted M. hapla J2 were counted from a 1-ml aliquot of the cleared sample under a Leica DM IL inverted microscope (Leica Microsystems, Wetzlar, Germany). The remaining soil in the sample was processed using a semiautomatic elutriator to recover all root material in the sample. M. hapla eggs were collected by removing egg masses adhering to roots retained from the $500-\mu \mathrm{m}$ sieve. Roots were gently washed on the sieve to remove debris, and large roots ( $>2 \mathrm{~mm}$ in diameter) were removed from the sample using tweezers. The remaining fine roots $(<2 \mathrm{~mm}$ in diameter) were removed from the sieve, blotted dry, and weighed. Fine roots were then placed into a $650-\mathrm{ml}$ screw-top container containing a $10 \%$ hypochlorite solution and shaken for 3 min to extract eggs from egg masses (Hussey and Barker 1973). The solution was then poured over stacked 88- and $25-\mu \mathrm{m}$ sieves to catch roots and eggs, respectively. Fine roots were removed from the $88-\mu \mathrm{m}$ sieve and stored in a fixative solution (10\% acetic acid, $50 \%$ ethanol) for subsequent processing (see below). The $25-\mu \mathrm{m}$ sieve containing eggs was backwashed into a 50$\mathrm{ml}$ tube and dyed with $0.35 \%$ acid fuchsin (Byrd et al. 1972) to facilitate counting. Eggs were counted from a 1-ml aliquot of the dyed solution under a Leica DM IL inverted microscope. A separate 50 -g subsample of soil was also retained and dried in a soil oven at $70^{\circ} \mathrm{C}$ for 7 days to determine the gravimetric water content.

Fine root analysis and $M$. hapla female density determination. Preserved root samples containing small woody and fine feeder roots were placed on a $500-\mu \mathrm{m}$ sieve and rinsed with water to remove root fixative. Roots were then spread across a large (15-cm diameter) Petri dish and examined under a stereoscope, and the fine roots with an intact cortex were cut from older roots as needed and transferred to a small (10-cm diameter) Petri dish with tweezers. The number of fine root tips in each sample was counted under a stereoscope. After counting root tips, the roots were further processed to stain females inside roots with acid fuchsin according to the method of Byrd et al. (1983). Destained roots containing females were spread across a large Petri dish, and females now stained red inside roots were counted under a stereomicroscope.

Collection of environmental data. Environmental data using weather stations closest to the sites was downloaded from AgWeatherNet (https://weather.wsu.edu; "Alderdale" at $1.3 \mathrm{~km}$ from Alderdale site; "McClure" at $22.6 \mathrm{~km}$ from Mattawa site, and "WSU Prosser" at $1.8 \mathrm{~km}$ from Prosser site). AgWeatherNet is a weather network maintained by Washington State University. The weather stations are equipped with Model 107 temperature probes (Campbell Scientific, Logan, UT) installed above ground $(1 \mathrm{~m})$ and $20.5 \mathrm{~cm}$ below the soil surface. They are also equipped with a rain sensor (Rain Gauge Tipping Bucket TR-5251; Texas Electronics, Dallas, TX). Data were collected in 15-min intervals, and daily averages were used in the development of the model (see below). These include average daily soil temperature, average daily air temperature, and average daily precipitation.

M. hapla developmental model construction. To develop the model, only data from the Mattawa site from 2015 and 2016 was used. The 2015 Alderdale and 2016 Prosser site data were used for validation; that is, to assess if the model developed from a single site (Mattawa) performed well at other vineyard sites (Alderdale and Prosser). Raw counts of $M$. hapla $\mathrm{J} 2$ per $250 \mathrm{~g}$ of soil were standardized to $\mathrm{J} 2$ per $250 \mathrm{~g}$ of dry soil by multiplying by the ratio of (mass of wet soil) to (mass of dry soil) for each sample. The five composite samples per collection date from each site were used to calculate the average $\mathrm{J} 2$ per $250 \mathrm{~g}$ of dry soil. To reduce variability in the data from the weekly sampling strategies, sampling dates were condensed by averaging weekly samples over 2 -week periods. Samples that were collected on a monthly timescale were not condensed. The average number of $\mathbf{J} 2$ per $250 \mathrm{~g}$ of dry soil was then converted to a percentage of maximum density (percent max) per year, by dividing the density at each sampling time by the greatest average density in that year. This allowed for between-site and between-year comparisons of $M$. hapla population dynamics.

Model development used the percent max J2 as the dependent variable. Soil growing degree days $\left(\mathrm{GDD}_{\text {soil }}\right)$ was used as the independent variable, and this was calculated using the following degree-day equation:

$$
\mathrm{GDD}_{\text {soil }}=\sum_{i=1}^{n}\left(\mathrm{~T}_{i}-\mathrm{T}_{\mathrm{b}}\right)
$$

where $\mathrm{T}_{i}=$ daily average soil temperature in degrees Celsius, $\mathrm{T}_{\mathrm{b}}=$ base temperature (multiple bases used; described below), and $n=$ 1 day, accumulated from a start date, which was selected as 1 March. This was used for all instances where $\mathrm{T}_{i}-\mathrm{T}_{\mathrm{b}}>0$. In the case where $\mathrm{T}_{i}$ $-\mathrm{T}_{\mathrm{b}} \leq 0$, the value 0 was used. $\mathrm{GDD}_{\text {soil }}$ was calculated using $\mathrm{T}_{\mathrm{b}}$ of 0 , 5 , and $10^{\circ} \mathrm{C}$. The minimum temperature for $M$. hapla development is likely between 8 and $10^{\circ} \mathrm{C}$ (Lahtinen et al. 1988; Tyler 1933). A final $\mathrm{T}_{\mathrm{b}}$ of $0^{\circ} \mathrm{C}$ was chosen based on data fitting described below and to more accurately capture potential development in a Washington temperate (cold-winter) climate.

Data sets were modeled in two parts: one modeling the decline in $M$. hapla $\mathrm{J} 2$ densities during the first half of the vine growing cycle and the second modeling the increase in M. hapla $\mathrm{J} 2$ densities in the 
second half of the vine growing cycle. The transition point between the two curves of $1,800 \mathrm{GDD}_{\text {soil }}$ was chosen to be just before the lowest $M$. hapla $\mathbf{J} 2$ density. Data specific to each curve were transformed to improve model fit using a $\ln (y)$ function for each base temperature $\left(\mathrm{T}_{\mathrm{b}}\right)$ of 0,5 , and $10^{\circ} \mathrm{C}$ using the Fit Special function in Bivariate fit (Fit $Y$ by $X$ ) platform in JMP 13.0.0 (SAS Institute, Cary, NC). Predicted values were calculated from each function of the form $\ln (y)=$ $\beta+\beta 1 \cdot x$, where $y$ is percent max $\mathrm{J} 2$ and $x$ is accumulated $\mathrm{GDD}_{\text {soil }}$. Linear regression of predicted values versus observed values was used to assess model fit, and $R^{2}$ and root mean squared error (RMSE) values were used to determine the best-fit model.

The models for both curves were then validated using data from the Alderdale and Prosser sites. These sites represented different cultivars of wine grape (Cabernet Sauvignon and Riesling), different years (2015 and 2016), and different areas of Washington State (Alderdale and Prosser). Linear regression of predicted values versus observed values was used to assess model fit. All statistical evaluations were done using JMP 13.0.0.

\section{Results}

Developmental dynamics of $M$. hapla in a Washington wine grape vineyard. In the Mattawa vineyard in 2015 and 2016, $M$. hapla appeared to complete a single generation per year. Seasonal trends were similar in both years for M. hapla J2 (Fig. 1A) and eggs (Fig. 1B). M. hapla J2 population densities were highest in early March before vine bud break (Fig. 1A). Densities of M. hapla J2 then declined from a high at $0 \mathrm{GDD}_{\text {soil }}\left(\mathrm{T}_{\mathrm{b}}\right.$ of $0^{\circ} \mathrm{C}$, starting 1 March) to their lowest point at 2,379 $\mathrm{GDD}_{\text {soil }}$ in 2015 (18 July) and 1,895 $\mathrm{GDD}_{\text {soil }}$ in 2016 (3 July). This coincided phenologically with lagphase (EL 35, extended BBCH scale; Lorenz et al. 1995) of berry development in both years. The BBCH scale is used to identify phenological stages of plant development; EL (Eichhorn-Lorenz) is an extension of that scale specifically designed for grapevine. Densities of $M$. hapla $\mathbf{J} 2$ then increased, reaching a maximum at $4,881 \mathrm{GDD}_{\text {soil }}$
A
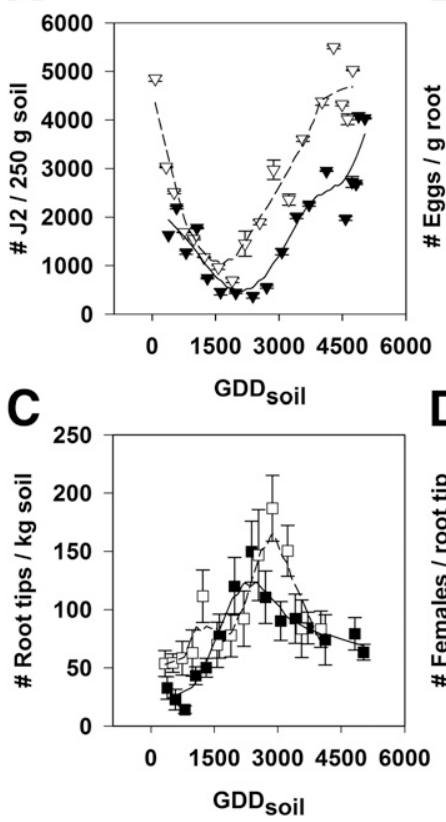

B
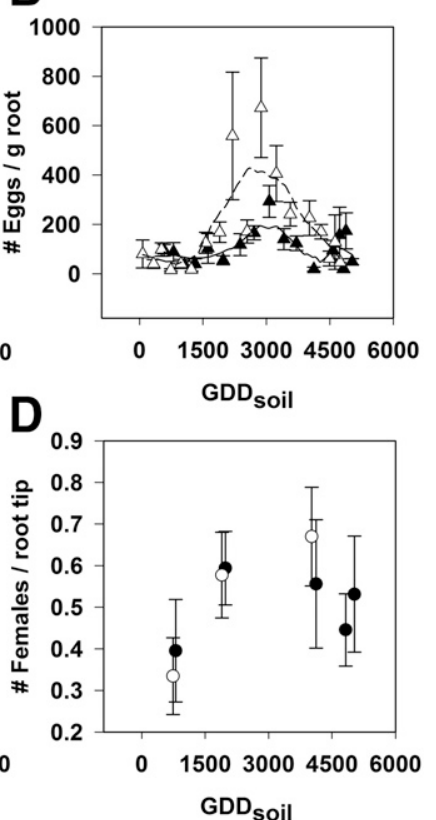

Fig. 1. Two-week average densities: A, Meloidogyne hapla second-stage juveniles (J2) (per $250 \mathrm{~g}$ of soil; downward triangle); B, eggs (per gram of root; upward triangle); $\mathbf{C}$, wine grape root tips (per kilogram of soil; square); and $\mathbf{D}$, females (per root tip; circle). Measurements taken at Mattawa, WA, vineyard March 2015 to March 2017 over soil growing degree days at $20.5 \mathrm{~cm}$ depth $\left(\mathrm{GDD}_{\text {soil }}\right)$ accumulated from 1 March at a temperature base of $0^{\circ} \mathrm{C}$. Filled symbols represent 2015-2016, and open symbols represent 2016-2017. Lines represent yearly trends: 2015-2016 (solid) and 2016-2017 (dashed). Each data point represents 10 (0 to 4,000 $\left.\mathrm{GDD}_{\text {soil }}\right)$ or $5\left(>4,000 \mathrm{GDD}_{\text {soil }}\right)$ observations, and error bars are standard error.
(14 January) in 2015 and 4,291 GDD soil (26 October) in 2016 (Fig. 1A). Accumulation of $\mathrm{GDD}_{\text {soil }}$ continued to a total of 5,029 GDD soil in 2015 and 4,744 GDD soil in 2016.

M. hapla egg densities reached a maximum at 3,069 $\mathrm{GDD}_{\text {soil }}$ in 2015 (14 August) and 2,871 GDD in 2016 (12 August; Fig. 1B). The peak in egg production at 2,800 to $3,100 \mathrm{GDD}_{\text {soil }}$ (midAugust) began approximately when $M$. hapla $\mathrm{J} 2$ were at minimum density and was followed closely by the increase in $M$. hapla $\mathrm{J} 2$ density. The pattern of root tip density closely followed that of $M$. hapla egg density (Fig. 1C), with maximums at 2,379 GDD $_{\text {soil }}$ in 2015 (18 July) and 2,871 GDD soil in 2016 (12 August). When assessed on a per root tip basis, densities of adult females per root remained relatively unchanged over time, around 0.5 females per root tip (Fig. 1D).

M. hapla developmental model. The life cycle of M. hapla was best modeled as two separate curves. Curve 1 (spring decline curve), which accounted for the early-season decline in M. hapla $\mathrm{J} 2$ density, was best described using $\mathrm{T}_{\mathrm{b}}$ of $0^{\circ} \mathrm{C}$ for calculating $\mathrm{GDD}_{\text {soil }}$, as noted by a fit with the highest $R^{2}(0.86)$ and lowest RMSE $(0.22)$, compared with the models using $\mathrm{T}_{\mathrm{b}}$ of $5^{\circ} \mathrm{C}\left(R^{2}=0.85\right.$, RMSE $\left.=0.22\right)$ or $10^{\circ} \mathrm{C}$ $\left(R^{2}=0.82\right.$, RMSE $\left.=0.25\right)$. Curve 2 (fall increase curve), which modeled the late-season increase in $M$. hapla $\mathrm{J} 2$ density, was the opposite, because calculating $\mathrm{GDD}_{\text {soil }}$ using $\mathrm{T}_{\mathrm{b}}$ of $0^{\circ} \mathrm{C}$ was less effective at describing $M$. hapla $\mathrm{J} 2$ densities over accumulated time/temperature $\left(R^{2}=0.73, \mathrm{RMSE}=0.39\right)$ than $5^{\circ} \mathrm{C}\left(R^{2}=0.73, \mathrm{RMSE}=0.39\right)$ or $10^{\circ} \mathrm{C}\left(R^{2}=0.75, \mathrm{RMSE}=0.37\right)$ for the fall increase in $\mathrm{J} 2$ density. We chose to use $0^{\circ} \mathrm{C}$ as our $\mathrm{T}_{\mathrm{b}}$ for $\mathrm{GDD}_{\text {soil }}$ calculations for model simplification because it was a better numeric fit for the earlyseason decline, despite being not as good a fit for the fall increase in M. hapla $\mathrm{J} 2$ as using $10^{\circ} \mathrm{C}$ (Fig. 2). Winter soil temperatures in the major grape growing regions of Washington state are often lower than $10^{\circ} \mathrm{C}$ but rarely drop below $0{ }^{\circ} \mathrm{C}$; all the subsequent $\mathrm{GDD}_{\text {soil }}$ were calculated from $\mathrm{T}_{\mathrm{b}}$ of $0^{\circ} \mathrm{C}$. The equation for curve 1 (spring decline) is

$$
\ln (y)=4.3871599-0.0010693 g x \text { for all } \mathrm{GDD}_{\text {soil }} \text { of } 0 \text { to } 1,800,
$$

and the equation for curve 2 (fall increase) is

$\ln (y)=1.5767586+0.000611 g x$ for all $\mathrm{GDD}_{\text {soil }}>1,800$,

where $y$ is the percent max of M. hapla $\mathrm{J} 2$ and $x$ is the accumulated $\mathrm{GDD}_{\text {soil }}$ at $\mathrm{T}_{\mathrm{b}}$ of $0^{\circ} \mathrm{C}$.

Inclusion of accumulated precipitation did not improve the model (data not shown). Because these are irrigated vineyards in an area with a yearly precipitation of $30 \mathrm{~cm}$ that falls predominately between October and April (WSU AgWeatherNet), the amount of soil water

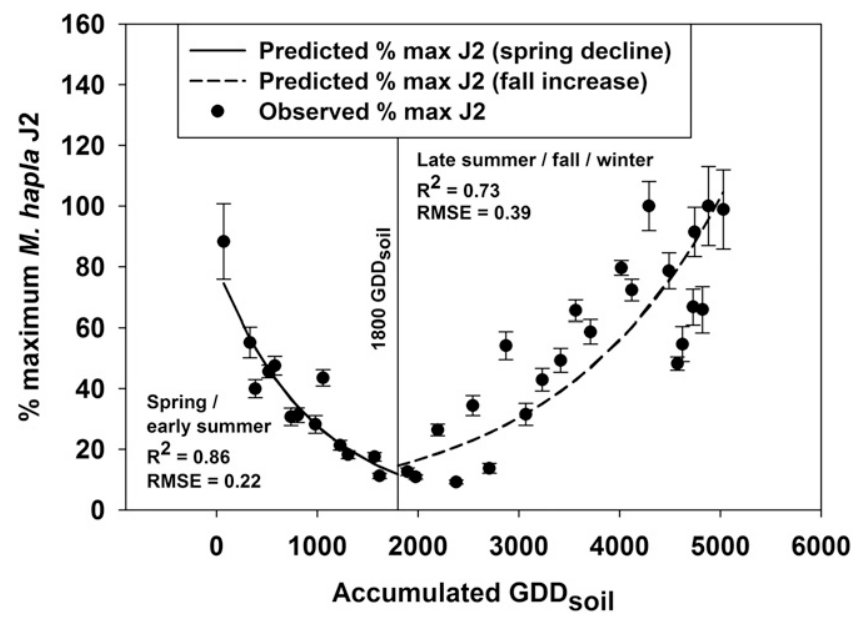

Fig. 2. Degree-day model for Meloidogyne hapla second-stage juveniles (J2) at Mattawa, WA. Observed M. hapla J2 percent maximum densities relative to the predicted percent maximum spring decline in $M$. hapla $\mathrm{J} 2$ (solid line) and fall increase in M. hapla J2 (dashed line) over soil growing degree days at $20.5 \mathrm{~cm}$ depth $\left(\mathrm{GDD}_{\text {soil }}\right)$ accumulated from 1 March at a temperature base of $0^{\circ} \mathrm{C}$. Error bars are standard error. 
from precipitation is likely less impactful on soil moisture than irrigation. We chose not to include air temperature in the model, because soil and air temperature were highly correlated $(r=0.93, P<0.0001$; March to February 2015 to 2017).

Validation of the M. hapla developmental model. The developed model was evaluated against two other vineyard data sets (Fig. 3). The minimum percent $\max M$. hapla $\mathrm{J} 2$ density for both sites was captured by the breaking point of $1,800 \mathrm{GDD}_{\text {soil }}$, and overall

A

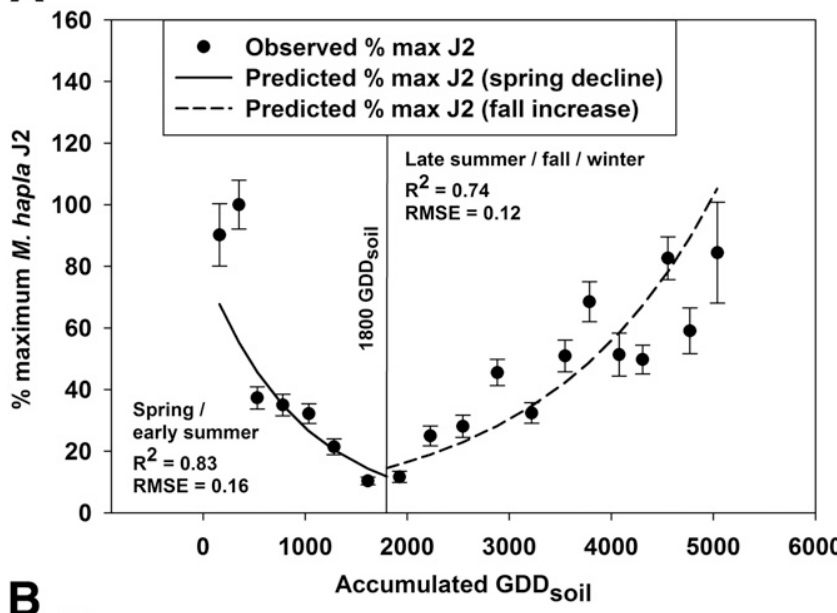

B

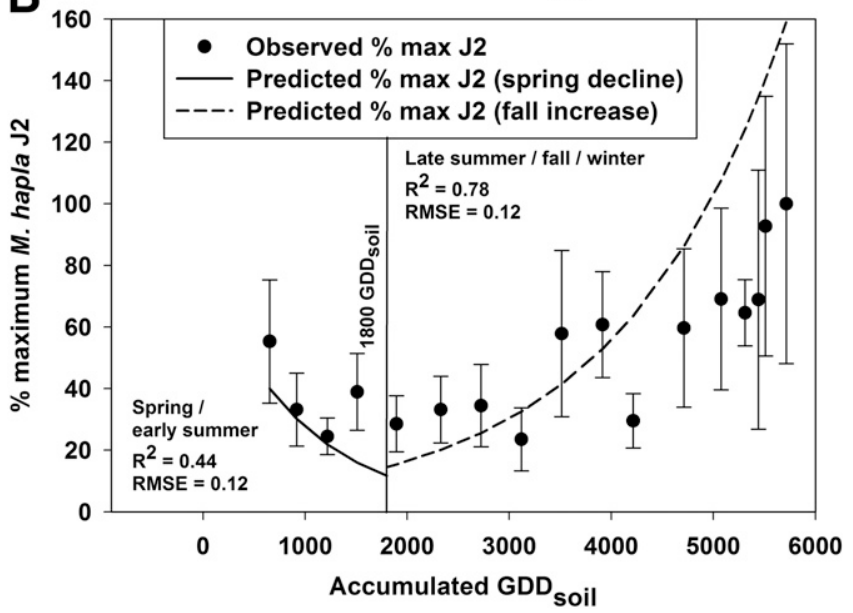

Fig. 3. Validation of degree day model at Prosser, WA (A) and Alderdale, WA (B) vineyards. Observed Meloidogyne hapla second-stage juveniles (J2) percent maximum densities relative to the predicted percent maximum spring decline in $M$. hapla J2 (solid line) and fall increase in M. hapla J2 (dashed line) over soil growing degree days at $20.5 \mathrm{~cm}$ depth $\left(\mathrm{GDD}_{\text {soil }}\right)$ accumulated from 1 March at a temperature base of $0^{\circ} \mathrm{C}$. Error bars are standard error. trends of $M$. hapla $\mathrm{J} 2$ density changes were similar at all three sites. The $M$. hapla J2 spring decline curve fit well $\left(R^{2}=0.83\right)$ for the Prosser vineyard (Fig. 3A) but less well for the Alderdale vineyard $\left(R^{2}=0.44\right)$ (Fig. 3B; Table 1). This may be partially owing to the small sample size at the Alderdale site in the spring; this site accumu-

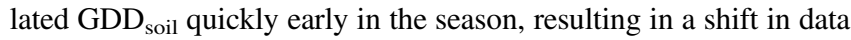
points from the first curve to the second. Both the Alderdale and Prosser vineyard observations were well explained by the fall increase curve, although at Alderdale the predicted M. hapla J2 densities were largely higher than the observed. The models tended to underestimate $M$. hapla $\mathrm{J} 2$ densities in spring and overestimate $M$. hapla $\mathrm{J} 2$ densities in fall at the Alderdale vineyard. This vineyard was highly variable in terms of nematode distribution, as is evidenced by the large standard errors in Figure 3B.

\section{Discussion}

Both the egg and $\mathrm{J} 2$ life stages of $M$. hapla had single annual peaks in eastern Washington wine grape vineyards, indicating that this nematode likely undergoes a single generation per year in this region. $M$. hapla $\mathrm{J} 2$ densities declined in the spring to a low in summer and then increased again to a maximum in the late fall to early winter. Although there is some constant egg and female presence over the winter, the major overwintering stage of $M$. hapla appears to be the $\mathrm{J} 2$ stage. M. hapla egg densities increased to a peak in early August and declined quickly as the new generation of $\mathrm{J} 2$ began to hatch in late summer to early fall. The density of root tips peaked at about the same timing as egg densities. The number of females per root tip remained relatively constant across the year; it follows that with increased root tip production that overall number of females per vine was maximal at the same time as root tips were. The peak in root tips may serve to align M. hapla development because (i) there are more fine roots available for invasion and subsequent female development, and (ii) there may be an increase in egg production owing to increased carbon supply to fine roots. This may explain why there is a definitive peak in egg production and a subsequent peak in $\mathrm{J} 2$. We cannot definitively say when the point of greatest $\mathbf{J} 2$ root invasion is occurring; further research would address this question.

The pattern of root tip growth observed here (coinciding with the peak in M. hapla egg density in midsummer) contrasts with the commonly reported pattern of grapevine root development in which root development peaks at two times per growing season: once around bloom (spring) and again in the fall (Mullins et al. 1992). Other studies, however, that have reported similar results (Bauerle et al. 2008; Eissenstat et al. 2006), in which a single peak of root growth occurred in midsummer. Those studies were conducted on irrigated 'Merlot' on rootstocks in Oakville, CA, which has a similar hot and dry growing season. Schreiner et al. (2007) also observed a single peak in fine root length density in an own-rooted Cabernet Sauvignon vineyard under regulated deficit irrigation in Paterson, WA. Because fine roots are the primary means to take up water and nutrients, if they are compromised by nematodes, a reduction in vine vigor over time would be expected. The method of root collection used here, however, only

Table 1. Linear regression statistics for predicted vs. observed percent maximum Meloidogyne hapla second-stage juveniles for curve $1\left(\mathrm{GDD}_{\text {soil }}<1,800\right)$ and curve $2\left(\mathrm{GDD}_{\text {soil }}>1,800\right)$ for the Prosser and Alderdale, WA, vineyard validation sites ${ }^{\mathrm{a}}$

\begin{tabular}{|c|c|c|c|c|c|c|c|}
\hline Location, curve & $N$ & $R^{2}$ & RMSE & Parameter & Parameter estimate & SE & $P$ value \\
\hline \multicolumn{8}{|l|}{ Prosser, WA } \\
\hline \multirow[t]{2}{*}{ Spring decline; $\mathrm{GDD}_{\text {soil }}<1,800$} & 7 & 0.83 & 15.5 & Intercept & -14.8 & 13.7 & 0.33 \\
\hline & & & & $y$ & 1.6 & 0.3 & 0.0043 \\
\hline \multirow[t]{2}{*}{ Fall increase; $\mathrm{GDD}_{\text {soil }}>1,800$} & 12 & 0.74 & 12.1 & Intercept & 15.4 & 7.2 & 0.058 \\
\hline & & & & $y$ & 0.7 & 0.1 & 0.0003 \\
\hline \multicolumn{8}{|l|}{ Alderdale, WA } \\
\hline \multirow[t]{2}{*}{ Spring decline; $\mathrm{GDD}_{\text {soil }}<1,800$} & 4 & 0.44 & 11.9 & Intercept & 15.8 & 18.8 & 0.49 \\
\hline & & & & $y$ & 0.8 & 0.7 & 0.34 \\
\hline \multirow[t]{2}{*}{ Fall increase; $\mathrm{GDD}_{\text {soil }}>1,800$} & 13 & 0.78 & 12.0 & Intercept & 22.6 & 6.2 & 0.0038 \\
\hline & & & & $y$ & 0.4 & 0.1 & $<0.0001$ \\
\hline
\end{tabular}

${ }^{\mathrm{a}} \mathrm{GDD}_{\text {soil }}=$ soil growing degree days at $20.5 \mathrm{~cm}$ depth; $N=$ sample size; $R^{2}=R$-squared value; $\mathrm{RMSE}=$ root mean squared error; and $\mathrm{SE}=$ standard error of the parameter estimate. 
captured fine roots in the wetted zone of drip irrigation and may not reflect potential root growth that occurred deeper in the soil profile. Our sampling method was specifically designed for the collection of roots for $M$. hapla egg extraction and was not optimized for fully assessing entire root systems or their temporal dynamics.

The pattern of $M$. hapla development reported here closely mimics that of M. chitwoodi on potato in eastern Washington (Pinkerton et al. 1991), in that there is a low density of J2 in midsummer and an increase in the fall. M. chitwoodi $\mathbf{J} 2$ densities were lowest from June to August and highest in September and October. Based on the infection of potato tubers, the authors interpreted the fall increase of M. chitwoodi $\mathbf{J} 2$ on potato as arising from multiple generations. However, their data could also be interpreted as a single generation with multiple cohorts of $\mathbf{J} 2$ that invaded potato roots in two to three different waves. Both M. hapla and M. chitwoodi are temperate species and must persist through subfreezing winters. Most Meloidogyne species found in warmer grape-growing regions can complete their life cycle within 30 days at soil temperatures typical for their regions (McKenry and Anwar 2006), resulting in potentially 12 generations and overlapping cohorts per year under optimal environmental conditions. In this situation, repeated nematicide applications would be required because an abundance of $\mathrm{J} 2$ would be present owing to multiple generations. This appears not to be the case for $M$. hapla in eastern Washington vineyards. Indeed, this study indicates that more specific timing for treatment (and fewer annual treatments overall) may be possible to improve $M$. hapla management.

Our data show that $M$. hapla overwinters primarily as $\mathrm{J} 2$, which are then present to infect new root tips in the spring. This is in contrast to $M$. incognita and $M$. arenaria, for which eggs were more likely to survive low soil temperatures than were J2 (Jeger and Starr 1985). Mature females of $M$. incognita were also found to overwinter and produce eggs the resulting spring at budbreak in a California vineyard, whereas J2 did not survive the winter (Melakeberhan et al. 1989). We found mature female $M$. hapla in roots in winter; however, because egg numbers were low from fall to spring, these females appeared not to produce new eggs during this time. This means that $M$. hapla $\mathrm{J} 2$ must persist in the soil for up to 6 months before infecting roots. M. naasi, another temperate species, is known to undergo a diapause in eggs that is broken by chilling (Van Gundy 1985), and retardation in hatching of $M$. incognita $\mathrm{J} 2$ from eggs has been described as dormancy (de Guiran 1979). There could be an environmental or host cue, such as increases in soil temperatures or metabolites produced by grapevine roots as they come out of dormancy, that affects the activity of M. hapla $\mathrm{J} 2$ in spring. Metabolic root activity of grapes resumes in spring, around when soil temperatures approach $7^{\circ} \mathrm{C}$ (Alleweldt 1965). All sites reached soil temperatures above $7^{\circ} \mathrm{C}$ by 7 March in both years. Further research on whether overwintering $M$. hapla $\mathrm{J} 2$ exhibit signs of dormancy would also provide an indication of factors that trigger $\mathrm{J} 2$ to come out of dormancy. Such knowledge could help identify management practices that might enhance overwinter mortality.

The life cycle model developed here was able to capture most (44 to $86 \%$ ) of the variation in the maximum $M$. hapla $\mathrm{J} 2$ density across multiple years and sites using only GDD $_{\text {soil }}$ as the independent variable. Knowing that nematodes progress through their life stages based on heat units, using $\mathrm{GDD}_{\text {soil }}$ rather than calendar date was chosen to model $\mathbf{J} 2$ densities. This also allows for the model to be useful in areas with varying site temperatures. Plotting J2 against $\mathrm{GDD}_{\text {soil }}$ follows a more cohesive curve than against calendar date, especially in colder times of the year. Because the highest densities of M. hapla $\mathrm{J} 2$ are in these cooler times of the year (September to March), having a model that fits well during these times was prioritized, especially for future use for sampling or nematicide scheduling. The model fit well to sites with different $M$. hapla pressure; $M$. hapla $\mathrm{J} 2$ densities at the Prosser site (average $400 \mathrm{~J} 2$ per $250 \mathrm{~g}$ of soil) were approximately six times lower than at the Mattawa site (average 2,340 J2 per $250 \mathrm{~g}$ of soil), with densities at the Alderdale site intermediate (average $1,100 \mathrm{~J} 2$ per $250 \mathrm{~g}$ of soil). One of the reasons the model may not have fit as well at the Alderdale site could be owing to a $V$. vinifera varietal difference (white versus red) between the
Mattawa and Alderdale site, respectively, which may also play a role in nematode development (Howland et al. 2015).

We developed and tested a life cycle model for M. hapla in Washington vineyards based on $\mathrm{GDD}_{\text {soil }}$ to determine when $\mathrm{J} 2$ are at a maximum in the soil. This model can also be used to help time postplant applications of nematicides or other nematode management techniques to target the most susceptible life stage of M. hapla. A degree-day model based on the study from Pinkerton et al. (1991) has been developed and is used to inform management decisions for fumigation and nematicide applications in potato for $M$. chitwoodi in the Pacific Northwest (Ingham et al. 2018). The model presented here for $M$. hapla could be used to improve timing of sampling to determine if population densities are above a critical threshold, and to improve nematicide timing in wine grapes in Washington state. If nematicides are to be used for $M$. hapla control, based on this model, the best timing is likely in fall. At this time, $\mathrm{J} 2$ densities in soil are increasing but have not yet reached a maximum. Further research is necessary to support any conclusions of nematicide timing.

\section{Acknowledgments}

Work presented here was completed by K. East in partial fulfillment of a Ph.D. in horticulture from Washington State University. Thank you to Ashley Boren, Elise Mills, Jensena Newhouse, Matthew Scott, Amy Peetz, and Keira Newell for their assistance. The authors also thank Joe Cotta of Ste. Michelle Wine Estates, Rick Hamman of Hogue Ranches, and Richard Hoff of Mercer Ranches for their technical assistance.

\section{Literature Cited}

Alleweldt, G. 1965. Über den Einfluss der Temperatur auf die Blutung von Reben Vitis 5:10-16.

Bauerle, T. L., Smart, D. R., Bauerle, W. L., Stockert, C., and Eissenstat, D. M. 2008. Root foraging in response to heterogeneous soil moisture in two grapevines that differ in potential growth rate. New Phytol. 179:857-866.

Byrd, D. W., Ferris, H., and Nusbaum, C. J. 1972. A method for estimating numbers of eggs of Meloidogyne sp. in soil. J. Nematol. 4:266-269.

Byrd, D. W., Kirkpatrick, T., and Barker, K. 1983. An improved technique for clearing and staining plant tissues for detection of nematodes. J. Nematol. 15: 142-143.

Chitwood, B. G. 1949. Root-knot nematodes. Proc. Helminth. Soc. Wash. 16: 90-104.

Daulton, R. A. C., and Nusbaum, C. J. 1961. The effect of soil temperature of the survival of the root-knot nematodes Meloidogyne javanica and M. hapla. Nematologica 6:280-294.

de Guiran, G. 1979. A necessary diapause in root-knot nematodes: Observations on its distribution and inheritance in Meloidogyne incognita. Rev. Nematol. 2:223-231.

de Guiran, G., and Ritter, M. 1979. Life cycle of Meloidogyne species and factors influencing their development. Pages 173-191 in: Root-Knot Nematodes (Meloidogyne Species): Systematics, Biology and Control. Lamberti, F., and Taylor, C. E., eds. Academic Press, New York.

Eisenback, J. D. 1985. Detailed morphology and anatomy of second-stage juveniles, males, and females of the genus Meloidogyne (root-knot nematodes). Pages 47-77 in: An Advanced Treatise on Meloidogyne, Vol. I. Biology and Control. K. R. Barker, C. C. Carter, and J. N. Sasser, eds. North Carolina State University Graphics, Raleigh.

Eisenback, J. D., Hirschmann, H., Sasser, J. N., and Triantaphyllou, A. C. 1981. A Guide to the Four Most Common Species of Root-Knot Nematodes (Meloidogyne spp.), with a Pictorial Key. North Carolina State University, Raleigh.

Eissenstat, D. M., Lakso, A. N., Nielsen, D., Smart, D. R., Bauerle, T. L., Comas, L. H., and Nielsen, G. H. 2006. Seasonal patterns of root growth in relation to shoot phenology in grape and apple. Acta Hortic. 721:21-26.

Howland, A. D., Schreiner, R. P., and Zasada, I. A. 2014. Spatial distribution of plant-parasitic nematodes in semi-arid Vitis vinifera vineyards in Washington. J. Nematol. 46:321-330.

Howland, A. D., Skinkis, P. A., Wilson, J. H., Riga, E., Pinkerton, J. N., Schreiner, R. P., and Zasada, I. A. 2015. Impact of grapevine (Vitis vinifera) varieties on reproduction of the northern root-knot nematode (Meloidogyne hapla). J. Nematol. 47:141-147.

Hussey, R. S., and Barker, R. K. 1973. Comparison of methods of collecting inocula of Meloidogyne spp., including a new technique. Plant Dis. Rep. 57: $1025-1028$

Ingham, R. E., Hamm, P. B., and Ocamb, C. M. 2018. Potato (Solanum tuberosum)-Nematode, Root-knot. In: Pacific Northwest Plant Disease Management Handbook. J. W. Pscheidt and C. M. Ocamb, eds. Oregon State University, Corvallis. https://pnwhandbooks.org/plantdisease/host-disease/ potato-solanum-tuberosum-nematode-root-knot

Jeger, M. J., and Starr, J. L. 1985. Dynamics of winter survival of eggs and juveniles of Meloidogyne incognita and Meloidogyne arenaria. J. Nematol. 17:252-256. 
Jenkins, W. R. 1964. A rapid centrifugal-flotation technique for separating nematodes from soil. Plant Dis. Rep. 48:692.

Lahtinen, A. E., Trudgill, D. L., and Tiilkkala, K. 1988. Threshold temperature and minimum thermal time requirements for the complete life cycle of Meloidogyne hapla from northern Europe. Nematologica 34:443-451.

Lorenz, D. H., Eichhorn, K. W., Bleiholder, H., Klose, R., Meier, U., and Weber, E. 1995. Growth stages of the grapevine: Phenological growth stages of the grapevine (Vitis vinifera L. ssp. vinifera) —Codes and descriptions according to the extended BBCH scale. Aust. J. Grape Wine Res. 1:100-103.

Lyons, J. M., Keith, A. D., and Thomason, I. J. 1975. Temperature-induced phase transitions in nematode lipids and their influence on respiration. J. Nematol. 7:98-104.

McKenry, M. V., and Anwar, S. A. 2006. Nematode and grape rootstock interactions including an improved understanding of tolerance. J. Nematol. 38:312-318.

McKenry, M. V., Buzo, T., Kretsch, J., Kaku, S., Otomo, E., Ashcroft, R., Lange, A., and Kelly, A. 1994. Soil fumigants provide multiple benefits; alternatives give mixed results. Calif. Agric. 48:22-28.

Melakeberhan, H., Ferris, H., McKenry, M. V., and Gaspard, J. T. 1989. Overwintering stages of Meloidogyne incognita in Vitis vinifera. J. Nematol. 21:92-98.

Mullins, M. G., Bouquet, A., and Williams, L. E. 1992. Biology of the Grapevine. Cambridge University Press, Cambridge, U.K.

NASS. 2017. Noncitrus Fruits and Nuts 2016 Summary. June 2017. https://www. nass.usda.gov/Publications/Todays_Reports/reports/ncit0617.pdf

Nicol, J. M., Stirling, G. R., Rose, B. J., May, P., and Van Heeswijck, R. 1999. Impact of nematodes on grapevine growth and productivity: Current knowledge and future directions, with special reference to Australian viticulture. Aust. J. Grape Wine Res. 5:109-127.

Pinkerton, J. N., Santo, G. S., and Mojtahedi, H. 1991. Population dynamics of Meloidogyne chitwoodi on Russet Burbank potatoes in relation to degree-day accumulation. J. Nematol. 23:283-290.

Raski, D. J., Hart, W. H., and Kasimatis, A. N. 1965. Nematodes and Their Control in Vineyards. California Agricultural Experiment Station Extension Circular 533.
Raski, D. J., Schmitt, R. V., Luvisi, D. A., and Kissler, J. J. 1973. 1,3-D and methyl bromide for control of root-knot and other nematodes in vineyard replants. Plant Dis. Rep. 57:619-623.

Schreiner, R. P., Tarara, J. M., and Smithyman, R. P. 2007. Deficit irrigation promotes arbuscular colonization of fine roots by mycorrhizal fungi in grapevine (Vitis vinifera L.) in an arid climate. Mycorrhiza 17:551-562.

Seinhorst, J. W. 1962. Modifications of the elutriation method for extracting nematodes from soil. Nematologica 8:117-128.

Taylor, A. L., and Buhrer, E. M. 1958. A preliminary report on the distribution of root-knot nematode in the United States. Phytopathology 48:464.

Taylor, A. L., and Sasser, J. N. 1978. Biology, Identification and Control of RootKnot Nematodes (Meloidogyne Species). North Carolina State University Graphics, Raleigh.

Thomason, I. J. 1962. Reaction of cereals and sudangrass to Meloidogyne spp. and the relation of soil temperature to Meloidogyne javanica population. Phytopathology 52:787-791.

Tyler, J. 1933. Development of the root-knot nematode as affected by temperature. Hilgardia 7:389-415.

Van Gundy, S. D. 1985. Ecology of Meloidogyne spp.-Emphasis on environmental factors affecting survival and pathogenicity. Pages 177-182 in: An Advanced Treatise on Meloidogyne, Vol. I. Biology and Control. K. R. Barker, C. C. Carter, and J. N. Sasser, eds. North Carolina State University Graphics, Raleigh.

Vrain, T. C., Barker, K. R., and Holtman, G. I. 1978. Influence of low temperature on rate of development of Meloidogyne incognita and $M$. hapla larvae. J. Nematol. 10:166-171.

Wallace, H. R. 1966. Factors influencing the infectivity of plant parasitic nematodes. Proc. R. Soc. Lond., B 164:592-614.

Zasada, I. A., Riga, E., Pinkerton, J. N., Wilson, J. H., and Schreiner, R. P. 2012. Plant-parasitic nematodes associated with grapevines, Vitis vinifera, in Washington and Idaho. Am. J. Enol. Vitic. 63:522-528. 